\title{
Isolation and characterization of microsatellite markers in the spiny lobster, Panulirus echinatus Smith, 1869 (Decapoda: Palinuridae) by Illumina MiSeq sequencing
}

\author{
MICHELLI F. SANTOS ${ }^{1,2}$, ISIS G. B. SOUZA ${ }^{1,2}$, SULIMARY O. GOMES ${ }^{1,2}$, GEICE R. SILVA ${ }^{1,2}$, \\ PAUL BENTZEN ${ }^{3}$ and FABIO M. DINIZ ${ }^{4,5 *}$ \\ ${ }^{1}$ Universidade Federal do Piaui, Campus Universitário Ministro Petrônio Portella, Ininga, Teresina, PI, 64049-550, Brazil \\ ${ }^{2}$ Universidade Federal do Piauí, Northeast Biotechnology Network RENORBIO, Teresina, PI, 64049-550, Brazil \\ ${ }^{3}$ Department of Biology, Dalhousie University, Halifax, NS, B3H 4J1, Canada \\ ${ }^{4}$ Empresa Brasileira de Pesquisa Agropecuária, Embrapa Meio-Norte, CP: 01, Teresina, PI, CEP: 64.006-220, Brazil \\ ${ }^{5}$ Empresa Brasileira de Pesquisa Agropecuária, Embrapa Caprinos e Ovinos, Caixa Postal: 145, Sobral, CE, CEP: 62010- \\ 970, Brazil \\ *For correspondence. E-mail: fabio.diniz@embrapa.br.
}

Received 22 February 2017; revised 12 May 2017; accepted 20 June 2017

Keywords. molecular markers; MiSeq sequencing; brown spiny lobster; population genetics.

\section{Introduction}

The isolation and characterization of 17 polymorphic microsatellite loci from the spiny lobster Panulirus echinatus (Decapoda: Palinuridae) by Illumina MiSeq sequencing is described. The analysis of genetic variability was performed in 42 individuals from 3 different populations (Saint Peter and Saint Paul Rocks, The Rocas Atoll and Cape Verde). The number of alleles ranged from 2 to 8 , with an average of $5.4 \pm 1.4$ alleles per locus. The values of allelic richness varied from 1.8 to 6.2 (average of $3.9 \pm 1.0$ ), while PIC values ranged between 0.173 and 0.811 . Overall mean observed and expected heterozygosity was estimated to be $0.418 \pm 0.165$ and $0.587 \pm 0.173$, respectively. These are the first microsatellite markers characterized for P. echinatus and it is expected that these markers will help to obtain the necessary information for developing conservation and management strategies for this highly valuable fishery species.

Lobster fisheries, undoubtedly, is one of the most financially valuable shellfish fisheries around the world, especially spiny and clawed lobsters. The brown spiny lobster Panulirus echinatus occurs on rocky reefs in the

Michelli F. Santos and Isis G. B. Souza contributed equally to this work. tropical western Atlantic Ocean and central Atlantic Islands (Holthuis 1991). The species is fished throughout its range, but intensively in some regions such as off Brazil, the islands of St Helena (UK), Cape Verde and the Canary Archipelago (Spain). Although commercially important fisheries exist for the species, the activity lacks management plan to ensure that lobster populations remain at sustainable levels. Fisheries legislation and other policy tools are not established for this lobster species in any of these countries. As biological information on P. echinatus is still scarce, it is of paramount importance to provide data that could be used to indicate whether an impact on the global population is existing.

Commercial fisheries in certain habitats may compromise distinct, locally adapted populations (Agardy 2000), resulting in loss of genetic diversity which is measured by the genetic variation distributed within as well as between populations (Scribner et al. 2016). Thus, the knowledge of genetic variability in P. echinatus and its populations is essential to aid in the management of fisheries stocks (e.g. Altukhov 1981; Shaklee and Samollow 1984).

Genetic data from molecular markers can be used to measure genetic differentiation and variability among marine populations, and therefore, address questions of 
fishery management relevance (e.g. identification of population and conservation units).

So far, only very few papers have been found in the literature containing more than distribution records on this species (e.g. site-specific population and reproductive biology of $P$. echinatus, Pinheiro et al. 2003; Pinheiro and Lins-Oliveira 2006; molecular identification of phyllosoma larva, Konishi et al. 2006; measurements of biometric relationships, Barreto et al. 2009), therefore, very little is known about the population diversity of $P$. echinatus.

Polymorphic simple sequence repeat (SSR) markers, also known as microsatellites, are useful molecular markers for fisheries population and conservation genetic studies due to their levels of intraspecific variability in many taxa, a consequence of the high mutation rate of these noncoding regions (Wright and Bentzen 1994). As no molecular markers have been identified in P. echinatus until now and the species has limited genomic information, it seems, therefore, an efficient alternative for microsatellite discovery and subsequent PCR primer design to use genome assembled Illumina paired-end DNA sequences via next-generation sequencing (NGS) technology (Abdelkrim et al. 2009).

In this study we have isolated and characterized a set of 20 SSR markers of trinucleotide and tetranucleotide motifs from P. echinatus using NGS.

\section{Materials and methods}

An Illumina paired-end library was created using $1 \mathrm{ng}$ of P. echinatus genomic DNA, following the standard protocol of the Illumina Nextera XT Library Preparation kit (Illumina, San Diego, USA). DNA was tagged and fragmented by the Nextera XT transposome, followed by limited-cycle PCR amplification, AMPure XP magneticbead purification (Agencourt Bioscience, Beverly, USA) and the Illumina Nextera XT bead-based normalization protocol. The DNA library was sequenced using a MiSeq Benchtop Sequencer (Illumina, San Diego, USA). Contigs were created from the resulting paired-end sequence data (reads) using CLC Genomics Workbench 7.0.4 (Qiagen).

All these contigs were subsequently input into Microsatellite Search Building Database (MSDB) (https:// github.com/lmdu/msdb; Du et al. 2013) for the detection of possible microsatellite loci with at least four repeats for trinucleotide and tetranucleotide motifs and designing of primer pairs for each detected locus at their flanking regions. Sequences with long mononucleotide repeat stretches were ignored for marker development. Primer design was performed with the Primer3 (Rozen and Skaletsky 2000).

A total of 42 individuals were sampled from three different localities within the central Atlantic Islands of Saint Peter and Saint Paul Rocks ( $0^{\circ} 55^{\prime} 2^{\prime \prime} \mathrm{N}, 29^{\circ} 20^{\prime} 44^{\prime \prime} \mathrm{W} ; 15$ individuals), The Rocas Atoll ( $3^{\circ} 51^{\prime} 50^{\prime \prime} \mathrm{S}, 33^{\circ} 48^{\prime} 48^{\prime \prime} \mathrm{W}$;
15 individuals), and Cape Verde $\left(14^{\circ} 55^{\prime} 0^{\prime \prime} \mathrm{N}, 23^{\circ} 31^{\prime} 0^{\prime \prime}\right.$ $\mathrm{W} ; 12$ individuals). Genomic DNA was isolated from the pereiopod (walking legs) muscle using phenolchloroform-isoamyl alcohol (25:24:1) extraction of the SDS/proteinase-K-digested tissue, followed by ethanol precipitation (Sambrook et al. 1989). DNA extracts from these samples were used to validate all designed primer pairs via PCR.

Reactions were performed in a $10 \mu \mathrm{L}$ total volume containing $\sim 20 \mathrm{ng}$ of genomic DNA, with $1.5 \mu \mathrm{L}$ of $10 \times$ buffer (Thermo Fisher Scientific, Waltham, USA), 2 to $2.5 \mathrm{mM} \mathrm{MgCl} 2$ (Thermo Fisher Scientific), $10 \mathrm{mM}$ dNTP mix (New England BioLabs), $0.25 \mathrm{mM}$ of each primer, $2.0 \mu \mathrm{L}$ de Q-solution (Qiagen, Hilden, Germany), and $1 \mathrm{U}$ of Taq DNA polymerase (Thermo Scientific). All amplifications were run in a Veriti 96-well Thermal Cycler (Applied Biosystems) using the following PCR-cycle conditions: $95^{\circ} \mathrm{C}$ for $10 \mathrm{~min}, 30 \times\left(1 \mathrm{~min}\right.$ at $95^{\circ} \mathrm{C}, 1 \mathrm{~min}$ at annealing temperature of $50-57^{\circ} \mathrm{C}$ depending on primer pair, $1 \mathrm{~min}$ at $72^{\circ} \mathrm{C}$ ), and $7 \mathrm{~min}$ at $72^{\circ} \mathrm{C}$. The amplification products were screened by silver nitrate detection on denatured $6 \%$ polyacrylamide gels.

The genotyped data was initially analysed using MicroChecker 2.2.3 (van Oosterhout et al. 2004) to test for the presence of null alleles, large alleles dropout and scoring errors by stuttering. Observed and expected heterozygosities $\left(H_{\mathrm{O}}\right.$ and $\left.H_{\mathrm{E}}\right)$, the number of alleles $(A)$, and the polymorphic information content (PIC) were determined using Cervus 3.0 (Kalinowski et al. 2007). Allelic richness $\left(A_{\mathrm{R}}\right)$ as a measure of the number of alleles per locus independent of the population size was calculated by FSTAT version 2.9.3.2 (Goudet 1995). Deviations from Hardy-Weinberg equilibrium (HWE) and tests for linkage disequilibrium were conducted using Genepop software (Raymond and Rousset 1995). The Bonferroni correction was applied when multiple pair-wise tests were performed to assess the significance $(P<0.05)$.

\section{Results and discussion}

The genomic library, previously loaded as $16 \%$ of a MiSeq Reagent Kit v2 300 cycle sequencing run, produced $3,232,259$ reads, which were assembled into 7196 contigs. The software MSDB identified 2959 microsatellite loci, being in the majority mononucleotide $(1290 ; 43.60 \%)$ and dinucleotide $(1280 ; 43.26 \%)$ repeats. For ease of imaging and scoring, we chose to examine only trinucleotide and tetranucleotide loci, respectively showing $221(7.47 \%)$ and $107(3.61 \%)$ repeats. From these, 27 loci were chosen for primer designing and validation of which 20 consistently amplified specific bands across individuals. Polymorphism was identified in 17 loci across the entire data set, the remaining three loci being monomorphic (Pech18, Pech19 and Pech20) (table 1). 


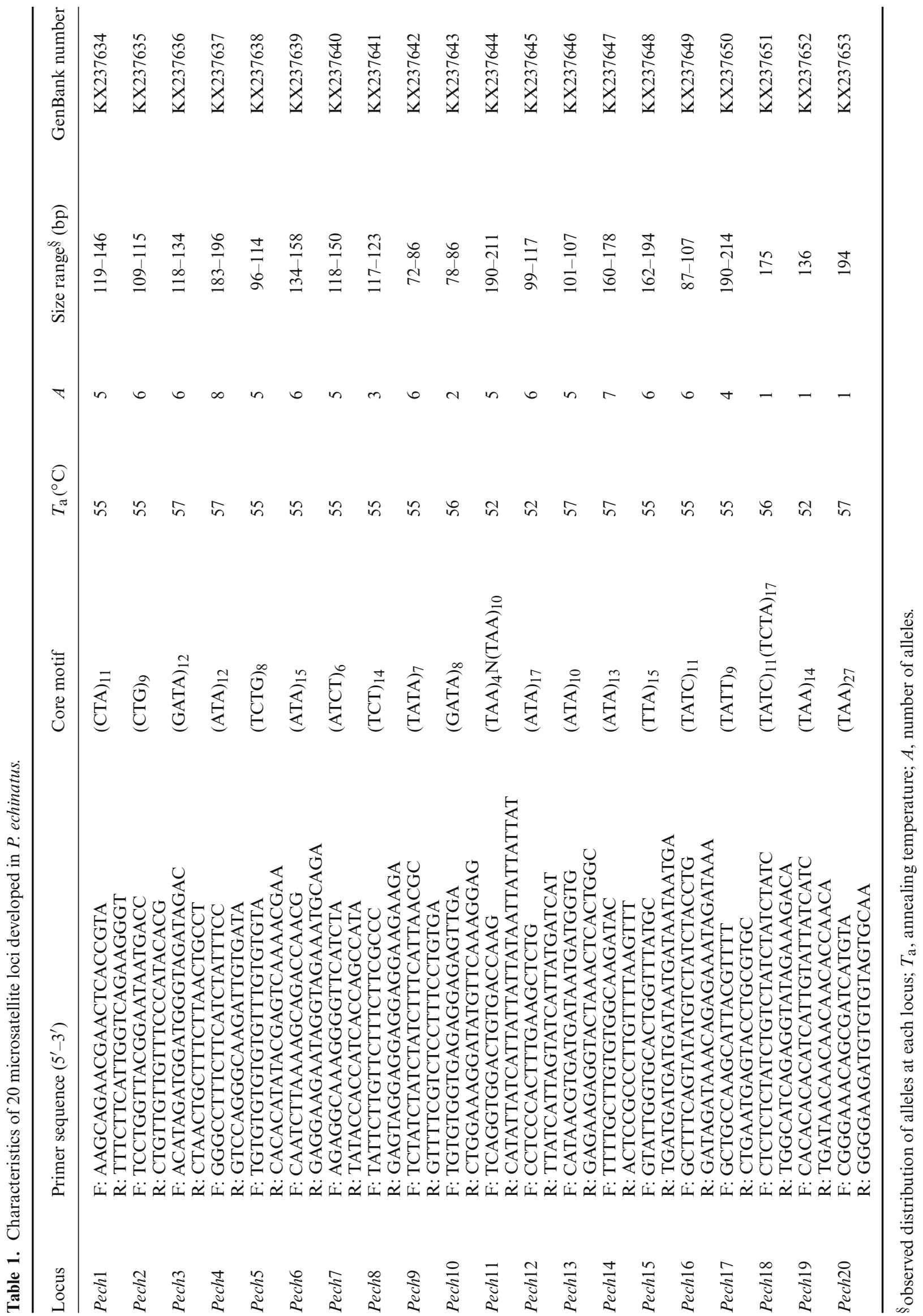


Table 2. Variability of 17 microsatellite loci and frequency of null alleles $P$. echinatus populations.

\begin{tabular}{lrllllrr}
\hline & \multicolumn{7}{c}{ All populations $(n=42)$} \\
\cline { 2 - 8 } Locus & $A_{\mathrm{R}}$ & $H_{\mathrm{O}}$ & $H_{\mathrm{E}}$ & PIC & $P_{\mathrm{HWE}}$ & \multicolumn{1}{c}{$F_{\mathrm{IS}}$} & \multicolumn{1}{c}{$F_{\text {Nulls }}$} \\
\hline Pech1 & 3.6 & 0.667 & 0.656 & 0.583 & 0.2629 & -0.0718 & -0.0112 \\
Pech2 & 4.0 & 0.595 & 0.660 & 0.589 & 0.1778 & 0.0806 & 0.0345 \\
Pech3 & 3.9 & 0.395 & 0.654 & 0.583 & $0.0006^{*}$ & 0.3998 & 0.1522 \\
Pech4 & 4.5 & 0.472 & 0.698 & 0.644 & $0.0004^{*}$ & 0.3155 & 0.1278 \\
Pech5 & 4.2 & 0.564 & 0.683 & 0.628 & 0.0616 & 0.1261 & 0.0656 \\
Pech6 & 4.7 & 0.415 & 0.755 & 0.704 & $0.0000^{*}$ & 0.4051 & 0.1899 \\
Pech7 & 3.3 & 0.424 & 0.493 & 0.439 & 0.3548 & 0.0820 & 0.0414 \\
Pech8 & 2.4 & 0.095 & 0.293 & 0.266 & $0.0000^{*}$ & 0.8609 & 0.1504 \\
Pech9 & 4.0 & 0.524 & 0.618 & 0.568 & 0.2030 & 0.1431 & 0.0542 \\
Pech10 & 1.8 & 0.214 & 0.194 & 0.173 & 1.0000 & -0.0943 & -0.0193 \\
Pech11 & 4.4 & 0.281 & 0.730 & 0.672 & $0.0000^{*}$ & 0.5892 & 0.2543 \\
Pech12 & 3.8 & 0.469 & 0.515 & 0.470 & 0.1240 & 0.0639 & 0.0256 \\
Pech13 & 3.5 & 0.524 & 0.616 & 0.538 & 0.1258 & 0.1517 & 0.0527 \\
Pech14 & 6.2 & 0.595 & 0.842 & 0.811 & $0.0005 *$ & 0.2696 & 0.1293 \\
Pech15 & 3.9 & 0.118 & 0.549 & 0.506 & $0.0000^{*}$ & 0.7747 & 0.2746 \\
Pech16 & 4.8 & 0.405 & 0.696 & 0.652 & $0.0010^{*}$ & 0.4045 & 0.1666 \\
Pech17 & 2.6 & 0.357 & 0.343 & 0.306 & 0.6560 & -0.0275 & -0.0140 \\
Mean & 3.8 & 0.418 & 0.587 & 0.537 & - & 0.2528 & - \\
\hline
\end{tabular}

$A_{\mathrm{R}}$, allelic richeness; $H_{\mathrm{O}}$, observed heterozygosity; $H_{\mathrm{E}}$, expected heterozygosity; PIC, polymorphic information content; $P_{\mathrm{HWE}}$, probabilities of departure from Hardy-Weinberg equilibrium (adjusted critical $P<0.0029$ ); * significant Hardy-Weinberg disequilibrium; $F_{\text {Nulls }}$, null allele frequency.

The analysis with the program Micro-Checker showed in a pool of sampled individuals the presence of low-tomoderate frequencies of null alleles in these loci which is not surprising as this is commonly observed in a variety of marine invertebrate species (Kaukinen et al. 2004; Dailianis et al. 2011). Null frequencies below 0.2 are acceptable in most microsatellite datasets (Dakin and Avise 2004). Only in two loci (Pech11 and Pech15) this estimate was higher than 0.2 . The most probable reason for occurrence of this phenomenon being scoring errors due to stuttering or large allele drop out. No loci showed significant linkage disequilibrium between any pair of loci after corrections for multiple comparisons.

The genotyping of the entire dataset $(N=42)$, with an overall frequency of missing single locus genotypes of 0.021 has also revealed 91 alleles at all 17 polymorphic loci, ranging from 2 (Pech10) to 8 (Pech4), with an average of $5.4 \pm 1.4$ alleles per locus (table 1 ). The number of alleles at trinucleotide and tetranucleotide microsatellites in spiny lobsters has been reported to vary from 5.3 for Brazilian P. argus (Diniz et al. 2005) to 11.9 for P. cygnus (Kennington et al. 2010).

The size of alleles in the most polymorphic locus, Pech14, based on $A_{\mathrm{R}}, H_{\mathrm{E}}$ and PIC varied from 160 to 178 . For the less polymorphic locus, Pech10, allele size ranged from 78 to $86 \mathrm{bp}$; a trinucleotide and tetranucleotide motif locus, respectively.
The level of polymorphism of each locus was also evaluated by the allelic richness $\left(A_{\mathrm{R}}\right)$, heterozygosities $(H)$ and the polymorphic information content (PIC) (table 2). The values of allelic richness varied from 1.8 to 6.2 (average of $3.9 \pm 1.0$ ), while PIC values ranged between 0.173 and 0.811 . Mean PIC $(0.537 \pm 0.165)$ characterize this set of microsatellite loci as highly informative markers, as defined by Botstein et al. (1980). Overall mean observed and expected heterozygosity was estimated to be $0.418 \pm 0.165$ and $0.587 \pm 0.173$, respectively. These estimates were higher when compared to mean $H_{\mathrm{O}}(0.265)$ and $H_{\mathrm{E}}(0.387)$ of the scalloped spiny lobster ( $P$. homarus) genotyped with microsatellite markers (Delghandi et al. 2015). However, $P$. echinatus heterozygosities were of lower magnitude when compared to other spiny lobsters, such as $P$. argus (Diniz et al. 2004, 2005; Tringali et al. 2008), P. cygnus (Kennington et al. 2010), P guttatus (Truelove et al. 2015), $P$. interruptus (Ben-Horin et al. 2009), and P. ornatus (Liu et al. 2013). Except for P. ornatus, all these lobster species belong to the same evolutionary lineage as indicated by mtDNA phylogeny (Ptacek et al. 2001).

Eight microsatellite loci exhibited significant probabilities of departure from HWE expectations after sequential Bonferroni correction, adjusted critical $P<0.0029$. In these cases, the deviations occurred in the form of heterozygote deficiency, perhaps resulting from the small sample size or, considering the potential for extensive gene 
flow in this species, the Wahlund effect (Johnson and Black 1984). Additionally, null alleles, even in low frequencies could have played an important part in the departures of HWE.

In this study, we report the isolation, using the NGS technology, and characterization of 17 polymorphic microsatellite loci for the brown spiny lobster P. echinatus. These microsatellites have demonstrated potential for population-level genetic studies and can provide valuable information on the genetic variation and stock structure of this lobster species. Therefore, we expect that these molecular markers will help to obtain the necessary information for developing conservation and management strategies for this highly valuable fishery species.

\section{Acknowledgements}

Sequencing was done on a MiSeq DNA sequencer purchased with a bequest from Elizabeth Ann Nielsen to the Marine Gene Probe Laboratory. The authors acknowledge financial support from the Brazilian Federal Government (Science without Borders programme) scholarship. The authors MFS, IGBS, SOG and GRS were supported by scholarships from the National Council for Scientific and Technological Development (CNPq).

\section{References}

Abdelkrim J., Robertson B. C., Stanton J. A. L. and Gemmell N. J. 2009 Fast, cost effective development of species specific microsatellite markers by genomic sequencing. Biotechniques 46, 185-192.

Agardy T. 2000 Effects of fisheries on marine ecosystems: a conservationist's perspective. ICES J. Mar. Sci. 57, 761-765.

Altukhov Y. 1981 The stock concept from the view point of population genetics. Can. J. Fish. Aquat. Sci. 38, 1523-1538.

Barreto A. V., Zani-Teixeira M. L., Ivo C. T. C. and Katsuragawa M. 2009 Biometric relationships of the spotted lobster, Panulirus echinatus, from Tamandaré coastal reefs, Pernambuco State, Brazil. J. Mar. Biol. Assoc. 89, 1601-1606.

Ben-Horin T., Iacchei M., Selkoe K. A., Mai T. T. and Toonen R. J. 2009 Characterization of eight polymorphic microsatellite loci for the California spiny lobster, Panulirus interruptus and cross-amplification in other achelate lobsters. Conserv. Genet. Resour. 1, 193-197.

Botstein D., White R. L. and Skolnick M. 1980 Construction of a genetic linkage map in man using restriction fragment length polymorphisms. Am. J. Hum. Genet. 32, 314-331.

Dailianis T., Tsigenopoulos C. S., Dounas C. and Voultsiadou E. 2011 Genetic diversity of the imperilled bath sponge Spongia officinalis Linnaeus, 1759 across the Mediterranean Sea: patterns of population differentiation and implications for taxonomy and conservation. Mol. Ecol. 20, 3757-3772.

Dakin E. E. and Avise J. C. 2004 Microsatellite null alleles in parentage analysis. Heredity 93, 504-509.

Delghandi M., Goddard S., Jerry D. R., Dao H. T., Afzal H. and Al-Jardani S. S. 2015 Isolation, characterization, and multiplexing of novel microsatellite markers for the tropical scalloped spiny lobster (Panulirus homarus). Genet. Mol. Res. 14, 19066-19070.

Diniz F. M., Maclean N., Paterson I. G. and Bentzen, P. 2004 Polymorphic tetranucleotide microsatellite markers in the
Caribbean spiny lobster, Panulirus argus. Mol. Ecol. Notes 4, 327-329.

Diniz F. M., Maclean N., Ogawa M., Paterson I. G. and Bentzen P. 2005 Microsatellites in the overexploited spiny lobster, Panulirus argus: Isolation, characterization of loci and potential for intraspecific variability studies. Conserv. Genet. 6, 637641.

Du L., Li Y., Zhang X. and Yue B. 2013 MSDB: a user-friendly program for reporting distribution and building databases of microsatellites from genome sequences. J. Hered. 104, 154157.

Goudet J. 1995 FSTAT Version 2.9.3.2: a computer program to calculate F-statistics. J. Hered. 86, 485-486.

Holthuis L. B. 1991 FAO species catalogue. Vol. 13. Marine lobsters of the world. An annotated and illustrated catalogue of species of interest to fisheries known to date. FAO Fish. Synopsis 125, 1-292.

Johnson M. S. and Black R. 1984 The Wahlund effect and the geographical scale of variation in the intertidal limpet Siphonaria sp. Mar. Biol. 79, 295-302.

Kalinowski S. T., Taper M. L. and Marshall T. C. 2007 Revising how the computer program CERVUS accommodates genotyping error increases success in paternity assignment. Mol. Ecol. 16, 1099-1106.

Kaukinen K. H., Supernault K. J. and Miller K. M. 2004 Enrichment of tetranucleotide microsatellite loci from invertebrate species. J. Shellfish Res. 23, 621-626.

Kennington W. J., Levy E., Berry O., Groth D. M., Waite A. M., Johnson M. S. and Melville-Smith R. 2010 Characterization of 18 polymorphic microsatellite loci for the western rock lobster Panulirus cygnus. Conserv. Genet. Resour. 2, 389-391.

Konishi K., Suzuki N. and Chow S. 2006 A late-stage phyllosoma larva of the spiny lobster Panulirus echinatus Smith, 1869 (Crustacea: Palinuridae) identified by DNA analysis. J. Plankton Res. 28, 841-845.

Liu L., Yang X. and Liu C. 2013 Eleven novel polymorphic microsatellite loci in the ornate spiny lobster Panulirus ornatus (Decapoda: Palinuridae). J. Genet. 92, e65-e67.

Pinheiro A. P., Freire F. A. M. and Lins-Oliveira J. E. 2003 Population biology of Panulirus echinatus Smith, 1869 (Decapoda: Palinuridae) from São Pedro e São Paulo archipelago, Northeastern Brazil. Nauplius 11, 27-35.

Pinheiro A. P. and Lins-Oliveira J. E. 2006 Reproductive biology of Panulirus echinatus (Crustacea: Palinuridae) from São Pedro and São Paulo archipelago, Brazil. Nauplius 14, 89-97.

Ptacek M. B., Sarver S. K., Childress M. J., Herrnkind W. F. 2001 Molecular phylogeny of the spiny lobster genus Panulirus (Decapoda: Palinuridae). Mar. Freshw. Res. 52, 10371047.

Raymond M. and Rousset F. 1995 An exact test for population differentiation. Evolution 49, 1280-1283.

Rozen S. and Skaletsky H. 2000 Primer3 on the WWW for general users and for biologist programmers. Methods Mol. Biol . 132, $365-386$

Sambrook J., Fritsch E. F. and Maniatis T. 1989 Molecular cloning: a laboratory manual, pp. 1626. Cold Spring Harbor Laboratory Press, New York.

Scribner K. T., Lowe W. H., Landguth E., Luikart G., Infante D. M., Whelan G. E. and Muhlfeld C. C. 2016 Applications of genetic data to improve management and conservation of river fishes and their habitats. Fisheries 41, 174 188

Shaklee J. B. and Samollow P. B. 1984 Genetic variation and population structure in a spiny lobster, Panulirus marginatus, in the Hawaiian Archipelago. Fish. Bull. 82, 693-702.

Tringali M. D., Seyoum S. and Schmitt S. L. 2008 Ten di- and trinucleotide microsatellite loci in the Caribbean spiny lobster, 
Panulirus argus, for studies of regional population connectivity. Mol. Ecol. Resour. 8, 650-652.

Truelove N. K., Behringer D. C., Butler IV M. J. and Preziosi R. F. 2015 Genetic analysis reveals temporal population structure in Caribbean spiny lobster (Panulirus argus) within marine protected areas in Mexico. Fish. Res . 172, 44- 49. van Oosterhout C., Hutchinson W. F., Wills D. P. M. and Shipley P. 2004 Micro-Checker: software for identifying and correcting genotyping errors in microsatellite data. Mol. Ecol. Notes 4, 535-538.

Wright J. M. and Bentzen P. 1994 Microsatellites - genetic markers for the future. Rev. Fish Biol. Fisher. 4, 384-388.

Corresponding editor: INDRAJIT NANDA 